\title{
Sulfur isotopic characteristics of volcanic products from the September 2014 Mount Ontake eruption, Japan
}

\author{
Kei Ikehata ${ }^{*}$ and Teruyuki Maruoka
}

\begin{abstract}
Components and sulfur isotopic compositions of pyroclastic materials from the $2014 \mathrm{Mt}$. Ontake eruption were investigated. The volcanic ash samples were found to be composed of altered volcanic fragments, alunite, anhydrite, biotite, cristobalite, gypsum, ilmenite, kaolin minerals, native sulfur, orthopyroxene, plagioclase, potassium feldspar, pyrite, pyrophyllite, quartz, rutile, and smectite, and most of these minerals were likely derived from the acidic alteration zones of Mt. Ontake. The absence of juvenile material in the eruptive products indicates that the eruption was phreatic. The sulfur isotopic compositions of the water-leached sulfate, hydrochloric acid-leached sulfate, acetone-leached native sulfur, and pyrite of the samples indicate that these sulfur species were produced by disproportionation of magmatic $\mathrm{SO}_{2}$ in the hydrothermal system at temperatures of $270-281^{\circ} \mathrm{C}$. This temperature range is consistent with that inferred from the hydrothermal mineral assemblage (e.g., pyrophyllite and rutile) in the 2014 pyroclastic materials $\left(200-300^{\circ} \mathrm{C}\right.$ ). Except for the sulfur isotopic compositions of anhydrite, which may have been altered by incorporation of sulfate minerals in a fumarolic area with lower sulfur isotopic values into the underground materials during the 1979 eruption, no significant differences in the mineral assemblages and sulfur isotopic compositions of the pyroclastic materials were identified between the products of the 2014 and 1979 Ontake phreatic eruptions, which suggests geochemical similarities in the underlying hydrothermal systems before the 2014 and 1979 eruptions.
\end{abstract}

Keywords: Mount Ontake, Phreatic eruption, Sulfur isotopic composition, Hydrothermal minerals

\section{Introduction}

Mount Ontake $\left(35^{\circ} 53^{\prime} 34^{\prime \prime} \mathrm{N}, 137^{\circ} 28^{\prime} 49^{\prime \prime} \mathrm{E}\right.$; Fig. 1) is the second highest volcano in Japan (elevation: $3067 \mathrm{~m}$ ). Few phreatic eruptions have been reported around the Jigokudani and Hachotarumi areas in recorded history (Oikawa 2008). On September 27, 2014, this volcano suddenly erupted pyroclastic material and volcanic gases. The craters formed in 2014 occurred in a different location from the previously formed craters of this volcano (Kaneko et al. 2014). The abundance of hydrothermal minerals such as anhydrite and pyrite, as well as the lack of juvenile material in the eruptive products, indicates that the 2014 eruption was essentially phreatic in nature (e.g., Ikehata et al. 2014; Imura et al. 2014; Miyagi et al.

\footnotetext{
*Correspondence: ikkei@geol.tsukuba.ac.jp

Faculty of Life and Environmental Sciences, University of Tsukuba, 1-1-1 Tennodai, Tsukuba, Ibaraki 305-8577, Japan
}

2014; Nakada et al. 2014). Sulfur isotopes have been used as geochemical tracers and temperature indicators for volcanic hydrothermal systems (e.g., Sugiura et al. 1980; Kusakabe et al. 1982; Ossaka et al. 1983; Williams et al. 1990). Kusakabe et al. (1982) reported sulfur isotopic compositions of anhydrite, pyrite, and native sulfur in pyroclastic materials from the phreatic eruption of Mt. Ontake on October 28, 1979. These authors concluded that some of the anhydrite and native sulfur were formed through the disproportionation reaction of sulfite produced by dissolution of magmatic $\mathrm{SO}_{2}$ into water in the mud reservoir below the crater zone. On the basis of the sulfur isotopic compositions of volcanic gases emitted during the 1979 Ontake eruption, the underground temperature of the crater area in 1979 was calculated to be higher than $250{ }^{\circ} \mathrm{C}$ (Ossaka et al. 1983). In this paper, we present sulfur isotopic data of sulfur-bearing minerals and components in the pyroclastic materials from the 


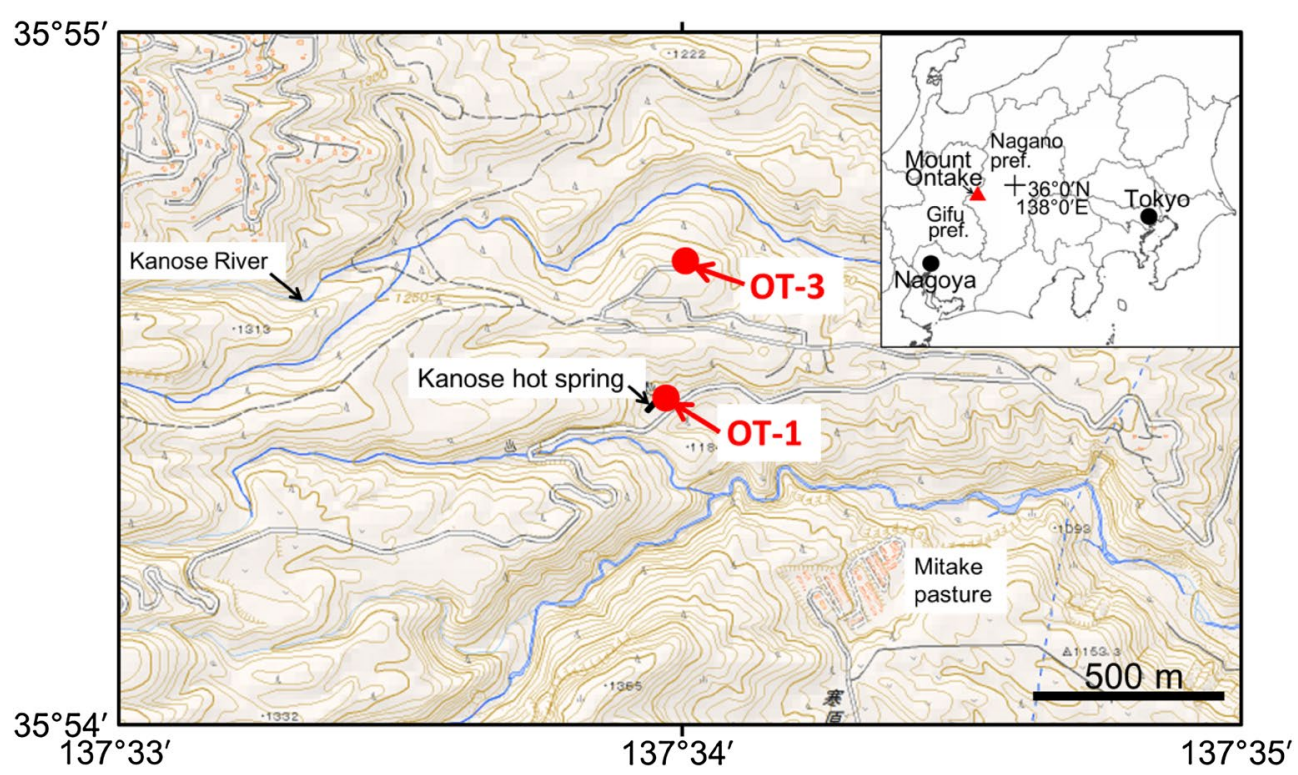

Fig. 1 Locality map of the sampling points for pyroclastic material, OT-1 and OT-3. OT-1 is located at the Kanose hot spring, about 8 km east-northeast of the Jigokudani area of Mt. Ontake, and OT-3 is located about $400 \mathrm{~m}$ north of the Kanose hot spring. Inset shows the location of Mt. Ontake. These maps are based on the GSI Maps by the Geospatial Information Authority of Japan

2014 Ontake eruption to elucidate the geochemical characteristics of the underlying hydrothermal system.

\section{Sampling locations and analytical methods}

Pyroclastic materials from the 2014 Ontake eruption were collected in the morning of September 30, 2014, from two locations near the Kanose hot spring, about $8 \mathrm{~km}$ east-northeast of the Jigokudani area of Mt. Ontake: OT-1, a roof of garden shed at the hot spring (Figs. 1, 2), and OT-3, a roadside garbage box located about $400 \mathrm{~m}$ north of the hot spring (Figs. 1, 3). The thickness of the

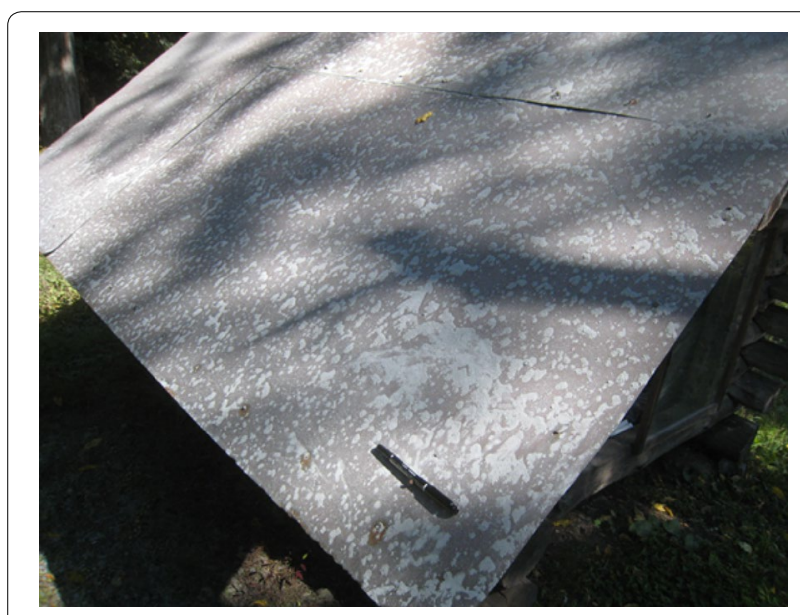

Fig. 2 Photograph of the sampling point of pyroclastic material OT-1, the roof of a garden shed at the Kanose hot spring, in the morning of September 30, 2014

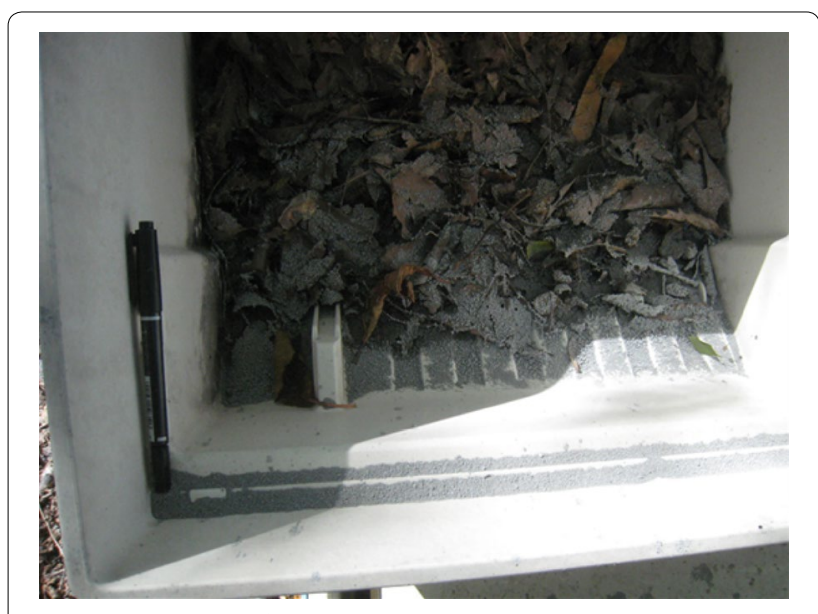

Fig. 3 Photograph of the sampling point of pyroclastic material OT-3, a roadside garbage box, in the morning of September 30, 2014

pyroclastic material deposited near the Kanose hot spring was about $1 \mathrm{~mm}$ (Fig. 4). The collected samples were unaffected by rainwater.

$\mathrm{X}$-ray diffraction (XRD) analyses were conducted to identify minerals in randomly oriented bulk sample (OT3 ) and air-dried oriented clay fractions $(<2 \mu \mathrm{m})$ separated through elutriation from the OT-3 sample. The clay-fraction samples were also examined with XRD after various treatments were applied (ethylene glycol treatment, $\mathrm{HCl}$ treatment, and heating at $500{ }^{\circ} \mathrm{C}$ ). Thin sections and epoxy 


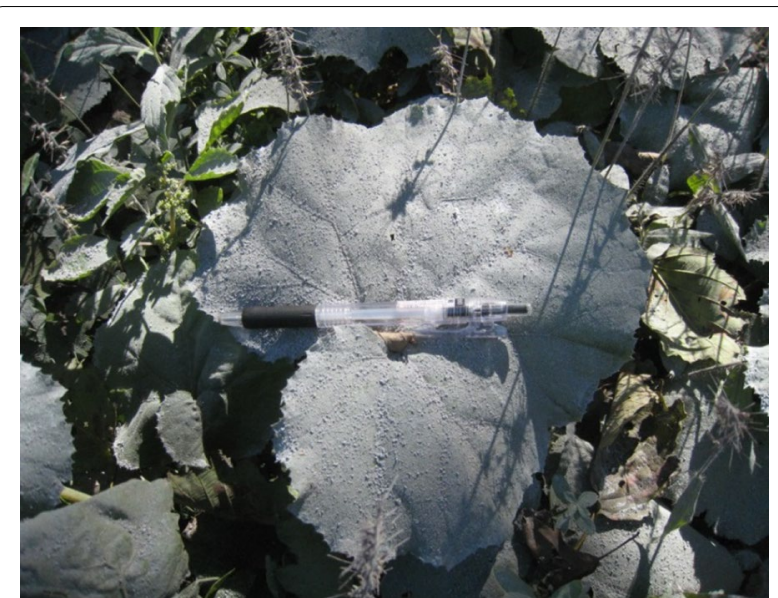

Fig. 4 Photograph of pyroclastic material deposited near the Kanose hot spring, about $8 \mathrm{~km}$ east-northeast of the Jigokudani area of Mt. Ontake in the morning of September 30,2014. The thickness of the pyroclastic material deposited near the Kanose hot spring was about $1 \mathrm{~mm}$

mounts of selected samples were also prepared for petrographic studies and electron probe microanalysis (EPMA).

About $20 \mathrm{~g}$ of each of the bulk ash samples (18.9 and $20.9 \mathrm{~g}$ of OT-1 and OT-3, respectively) was soaked for $12 \mathrm{~h}$ in $800 \mathrm{ml}$ of $18 \mathrm{M} \Omega$ deionized water. The supernatant liquid from each sample was then separated from the $\mathrm{H}_{2} \mathrm{O}$ solution through filtration using mixed cellulose ester membrane filters with pore sizes of $0.2 \mu \mathrm{m}$ (Advantec Tokyo, Japan). The $\mathrm{H}_{2} \mathrm{O}$-soaked ash samples were then rinsed with deionized water twice. To ensure oxidation of elemental sulfur, $5 \mathrm{ml}$ of $30 \%$ hydrogen peroxide was added to each of the remaining solutions. These solutions were acidified to a $\mathrm{pH}$ of about 3 by adding $2 \mathrm{~N}$ $\mathrm{HCl}$. Forty milliliters of $10 \% \mathrm{BaCl}_{2}$ solution was added to the solutions to precipitate barium sulfate. The barium sulfate samples precipitated from the $\mathrm{H}_{2} \mathrm{O}$ solutions (water-leached sulfate, $\mathrm{H}_{2} \mathrm{O}-\mathrm{S}$ ) were collected through filtration and rinsed with deionized water. The $\mathrm{H}_{2} \mathrm{O}$-soaked ash samples were treated with $150 \mathrm{ml}$ of $2 \mathrm{~N} \mathrm{HCl}$ for $2 \mathrm{~h}$ at $80{ }^{\circ} \mathrm{C}$. After membrane filtration, the $\mathrm{pH}$ of each solution was adjusted to about 2 through the addition of $6 \mathrm{~N}$ $\mathrm{KOH} ; 20 \mathrm{ml}$ of $10 \% \mathrm{BaCl}_{2}$ solution was then added to the $\mathrm{HCl}$ solutions to precipitate barium sulfate. The barium sulfate samples precipitated from the $\mathrm{HCl}$-treated solutions (hydrochloric acid-leached sulfate, $\mathrm{HCl}-\mathrm{S}$ ) were collected through filtration and rinsed with deionized water. Pyritic sulfide samples (Pyrite-S) were collected from a portion of the acid-treated ash samples (about $2 \mathrm{~g}$ ) through a density separation method using 1,1,2,2-tetrabromoethane $\left(2.967 \mathrm{~g} / \mathrm{cm}^{3}\right)$. Hundred milliliters of acetone was added to the remaining portion of the $\mathrm{HCl}$ treated ash samples. The acetone solutions were filtered with glass fiber filters (GC-50, Advantec, Tokyo, Japan) and dried in a vacuum chamber at $0.02 \mathrm{MPa}$ at room temperature to obtain evaporated residue of elemental sulfur from the acetone solutions (acetone-leached native sulfur, Native-S).

Sulfur isotopic compositions were determined for the barium sulfate precipitates and the pyritic and elemental sulfur using a helium gas continuous-flow isotope ratio mass spectrometer (CF-IR-MS; Isoprime-EA; Isoprime Ltd., UK) at the University of Tsukuba (see Maruoka et al. 2003a). The samples were weighed in $3.3 \mathrm{~mm} \times 5 \mathrm{~mm}$ tin capsules, and 200-300 $\mu$ g of $\mathrm{V}_{2} \mathrm{O}_{5}$ was added to each sample. The tin-wrapped samples were introduced into a combustion/reduction quartz tube with an autosampler and were heated at $1070{ }^{\circ} \mathrm{C}$ with a helium gas flow of $120 \mathrm{ml} / \mathrm{min}$. The samples were then oxidized with pulses of oxygen. The combustion/reduction tube contained tungstic trioxide to promote the complete oxidation of the samples and pure copper wires to remove excess oxygen and to convert sulfur trioxide to sulfur dioxide. The water produced during combustion was removed by a water trap of magnesium perchlorate. The gases were then introduced into the quartz tube, which contained quartz wool, and held at $890^{\circ} \mathrm{C}$ to minimize the oxygen isotope variation of the $\mathrm{SO}_{2}$, with a $\mathrm{SO}_{2}-\mathrm{SiO}_{2}$ equilibrium reaction (Fry et al. 2002). Sulfur dioxide and other gases, such as $\mathrm{CO}_{2}$ and $\mathrm{N}_{2}$, were separated through gas chromatography. These gases were then introduced with continuous flow of helium into the mass spectrometer through an open-split interface.

The sulfur isotopic compositions are expressed in terms of $\delta^{34} \mathrm{~S}(\%)$ relative to the V-CDT (Vienna-Canyon Diablo Troilite) standard. The results of three IAEA (International Atomic Energy Agency) silver sulfide standards (IAEA-S-1, $-0.3 \%$; IAEA-S-2, +21.80\% \% and IAEA-S-3, -31.95\%; Mayer and Krouse 2004) were compared to constrain the $\delta^{34} \mathrm{~S}$ values. The isotopic compositions of sulfur were determined to a precision of $\pm 0.1 \%$ o $(1 \sigma)$ for $30 \mu \mathrm{g}$ of sulfur. Precisions were determined based on a combination of the standard deviations from repeated analyses of the samples and standards (Maruoka et al. 2003b); the sample analyses were repeated at least four times.

\section{Results and discussion}

\section{Sample description}

The collected samples (OT-1 and OT-3) consisted of spherical aggregates of grayish fine volcanic ash (Fig. 5). Stereomicroscopic observation of these samples revealed the presence of clay minerals, hydrothermally altered fragments with sulfate minerals and pyrite, and free crystals of pyrite, feldspar, and silica mineral in both the samples (Fig. 6). No juvenile materials were found in the samples. Alunite, anhydrite, biotite, cristobalite, gypsum, 


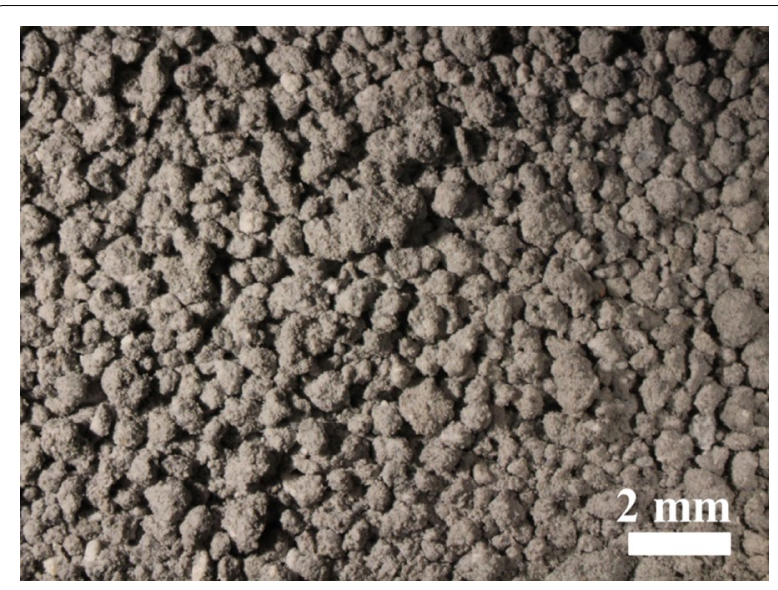

Fig. 5 Photomicrograph of the unwashed pyroclastic material (OT-1) of the 2014 Mt. Ontake eruption under a stereomicroscope

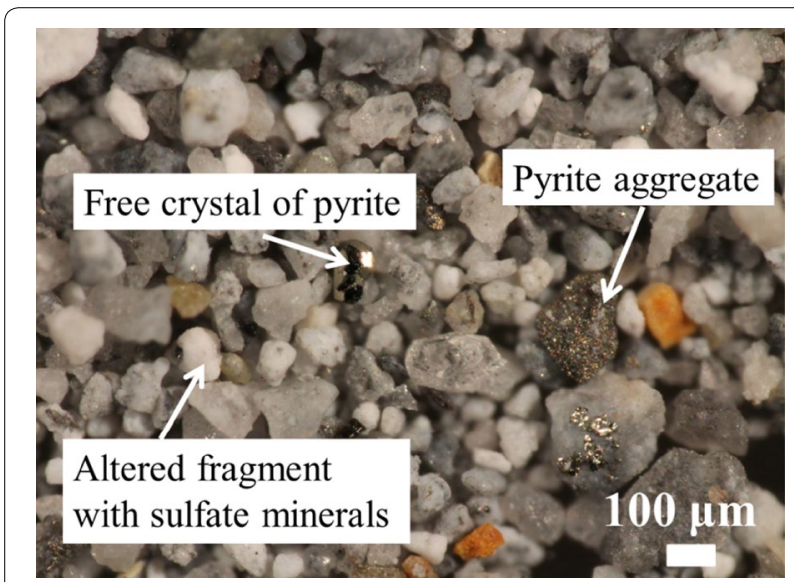

Fig. 6 Photomicrograph of the washed pyroclastic material (OT-1) of the 2014 Mt. Ontake eruption under a stereomicroscope

kaolin minerals, plagioclase, pyrite, pyrophyllite, quartz, and smectite were identified with XRD analyses of the randomly oriented bulk sample (OT-3) and oriented clay fractions of the OT-3 sample (Fig. 7). Ilmenite, orthopyroxene, potassium feldspar, and rutile were also found in OT-3 by EPMA analysis and polarizing microscope observation. These hydrothermal minerals are commonly found in acidic alteration zones of active geothermal areas and sulfur fumaroles (e.g., Utada 1980; Hedenquist et al. 1996). Cristobalite and kaolin minerals are lowtemperature (i.e., less than $200{ }^{\circ} \mathrm{C}$ ) acid-stable minerals, whereas pyrophyllite and rutile are relatively high-temperature $\left(200-300{ }^{\circ} \mathrm{C}\right.$ ) acid-stable minerals (Hedenquist et al. 1996). Most of the hydrothermal minerals of the Mt. Ontake 2014 eruptive products were also reported from pyroclastic materials of the 1979 Mt. Ontake phreatic eruption (e.g., Sugiura et al. 1980; Ossaka et al. 1983), which suggests similarity in the temperature ranges of the hydrothermal systems of both eruptions.

\section{Sulfur isotopic characteristics}

Sulfur isotopic compositions of sulfur from the waterleached sulfate $\left(\mathrm{H}_{2} \mathrm{O}-\mathrm{S}\right)$, hydrochloric acid-leached sulfate ( $\mathrm{HCl}-\mathrm{S})$, acetone-leached native sulfur (Native-S), and pyrite (Pyrite-S) from the collected samples (OT-1 and OT-3) are presented in Table 1 and Fig. 8.

The $\delta^{34} \mathrm{~S}$ values of $\mathrm{H}_{2} \mathrm{O}-\mathrm{S}$ of OT-1 and OT-3 are $+15.53 \%$ and $+15.22 \%$ and are similar to those of the $\mathrm{HCl}-\mathrm{S}$ results of $+15.92 \%$ (OT- 1 ) and $+16.04 \%$ (OT-3), respectively. The sulfur isotopic compositions of the HCl-S for the 2014 Ontake phreatic eruption are slightly higher than those of the HCl-S from the 1979 Ontake phreatic eruption $\left(\delta^{34} \mathrm{~S}=+8.3 \%\right.$ to $+14.0 \%$; Kusakabe et al. 1982). The Native-S of OT-1 and OT-3 has $\delta^{34} \mathrm{~S}$ values of $-3.86 \%$ and $-3.77 \%$, respectively, and is within the reported range of the Native-S from the 1979 eruption $\left(\delta^{34} \mathrm{~S}=-5.3 \%\right.$ to $-1.8 \%$; Kusakabe et al. 1982). The $\delta^{34} \mathrm{~S}$ values of Pyrite-S of OT-1 and OT-3 are $-5.24 \%$ and $-5.17 \%$, in the same range as those of the Pyrite-S from the 1979 eruption $\left(\delta^{34} \mathrm{~S}=-6.4 \%\right.$ to $-5.4 \%$; Kusakabe et al. 1982). There are no significant differences in sulfur isotopic compositions of $\mathrm{H}_{2} \mathrm{O}$ S, HCl-S, Native-S, or Pyrite-S between OT-1 and OT-3. Isotopic fractionation between reduced sulfur and oxidized sulfur species occurs during disproportionation of magmatic $\mathrm{SO}_{2}$ in the presence of water through the following reaction (Holland 1965),

$$
4 \mathrm{SO}_{2}+4 \mathrm{H}_{2} \mathrm{O}=3 \mathrm{H}_{2} \mathrm{SO}_{4}+\mathrm{H}_{2} \mathrm{~S},
$$

which produce isotopically light sulfides and heavy sulfates (Ohmoto and Rye 1979; Rye 2005). The sulfur isotopic values of pyroclastic materials from the 2014 Ontake eruption can be explained by the reaction above occurring in the underlying hydrothermal system (mud reservoir), as proposed for the 1979 Ontake eruption and volcanic activities in other regions (e.g., Kusakabe et al. 1982; Williams et al. 1990). Also as proposed for the case of the 1979 Ontake eruption (Kusakabe et al. 1982), some native sulfur of the 2014 eruptive products was probably formed in the presence of water in the mud reservoir beneath Mt. Ontake through a different disproportionation reaction (Holland 1965),

$$
3 \mathrm{SO}_{2}+2 \mathrm{H}_{2} \mathrm{O}=2 \mathrm{H}_{2} \mathrm{SO}_{4}+\mathrm{S} .
$$

Kusakabe et al. (1982) also suggested that some native sulfur with heavier $\delta^{34} \mathrm{~S}$ values $(-3.6 \%$ to $-1.8 \%$ ) than the others $(-5.3 \%$ to $-5.1 \%$ ) was formed by oxidation of $\mathrm{H}_{2} \mathrm{~S}$ around fumaroles. Native sulfur with 

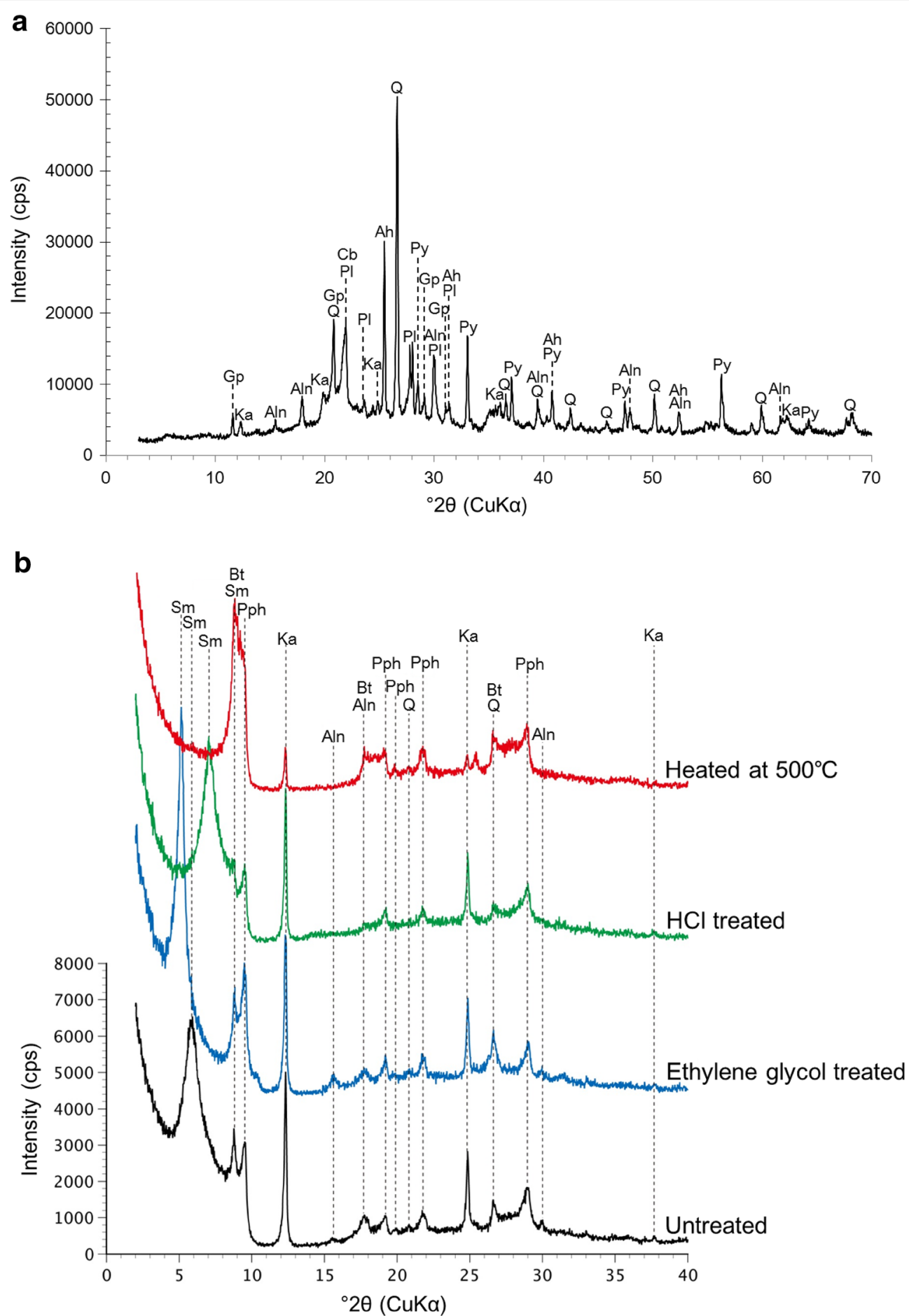

Fig. 7 X-ray diffraction (XRD) patterns of a randomly oriented bulk pyroclastic material (OT-3) and $\mathbf{b}$ oriented clay fractions $(<2 \mu \mathrm{m})$ separated through elutriation of the OT-3 sample from the 2014 Mt. Ontake eruption. The clay-fraction samples were examined with XRD after various treatments (ethylene glycol treatment, $\mathrm{HCl}$ treatment, and heating at $500^{\circ} \mathrm{C}$ ). Note that the smectite peak of the untreated clay fraction was shifted after the ethylene glycol, $\mathrm{HCl}$, and heating treatments. Abbreviations for minerals: Aln alunite, Ah anhydrite, Bt biotite, Cb cristobalite, Gp gypsum, Ka kaolin minerals, Pl plagioclase, Py pyrite, Pph pyrophyllite, Q quartz, Sm smectite 
Table 1 Sulfur isotopic values and concentrations of sulfur species of the pyroclastic materials of the $2014 \mathrm{Mt}$. Ontake eruption

\begin{tabular}{|c|c|c|c|c|}
\hline Sample & Sulfur species & $S(w t \%)$ & $\delta^{34} S(\% \circ)$ & $\pm 1 \sigma(\% o)$ \\
\hline OT-1 & $\begin{array}{l}\text { Water-leached sulfate } \\
\left(\mathrm{H}_{2} \mathrm{O}-\mathrm{S}\right)\end{array}$ & 0.50 & +15.53 & 0.10 \\
\hline OT-1 & $\begin{array}{l}\text { Hydrochloric acid-leached } \\
\text { sulfate (HCl-S) }\end{array}$ & 0.62 & +15.92 & 0.08 \\
\hline OT-1 & $\begin{array}{l}\text { Acetone-leached native } \\
\text { sulfur (Native-S) }\end{array}$ & 0.22 & -3.86 & 0.07 \\
\hline OT-1 & Pyrite (Pyrite-S) & $1.79^{\mathrm{a}}$ & -5.24 & $0.24^{b}$ \\
\hline OT-3 & $\begin{array}{l}\text { Water-leached sulfate } \\
\left(\mathrm{H}_{2} \mathrm{O}-\mathrm{S}\right)\end{array}$ & 0.54 & +15.22 & 0.09 \\
\hline OT-3 & $\begin{array}{l}\text { Hydrochloric acid-leached } \\
\text { sulfate (HCl-S) }\end{array}$ & 0.58 & +16.04 & 0.07 \\
\hline OT-3 & $\begin{array}{l}\text { Acetone-leached native } \\
\text { sulfur (Native-S) }\end{array}$ & 0.22 & -3.77 & 0.08 \\
\hline OT-3 & Pyrite (Pyrite-S) & $1.12^{\mathrm{a}}$ & -5.17 & $0.37^{b}$ \\
\hline
\end{tabular}

a Some pyrite grains attached to lighter minerals (e.g., silicate minerals) might not have precipitated during density separation; therefore, the values should be considered as minimum sulfur concentrations

b The errors for pyritic sulfur in this study were larger than the precision determined for other samples; however, such larger errors likely originated from isotopic heterogeneity

H.O-S (OT-1, OT-3)
HCI-S (OT-1, OT-3)
Native-S (OT-1, OT-3)
Pyrite-S (OT-1, OT-3)
HCl-S (1979 eruption)
Native-S (1979 erup tion)
Pyrite-S (1979 eruption)
Fig. 8 Diagram showing variations in $\delta^{34} \mathrm{~S}$ values of sulfur from
water-leached sulfate (H. $\left.{ }_{2} \mathrm{O}-\mathrm{S}\right)$, hydrochloric acid-leached sulfate (HCl-
S), acetone-leached native sulfur (Native-S), and pyrite (Pyrite-S) for
the pyroclastic materials of the OT-1 and OT-3 samples from the 2014
Mt. Ontake eruption compared to those of sulfur from hydrochloric
acid-leached sulfate (HCl-S), acetone-leached native sulfur (Native-S),
and pyrite (Pyrite-S) for the pyroclastic materials from the $1979 \mathrm{Mt}$.
Ontake eruption (Kusakabe et al. 1982)

a similar sulfur isotopic composition $\left(\delta^{34} \mathrm{~S}=-2.6 \%\right.$ ) was reported around fumaroles related to the $1979 \mathrm{Mt}$. Ontake eruption (Ossaka et al. 1983). If sulfur isotopic equilibrium between anhydrite and pyrite is assumed, the observed sulfur isotope fractionations of the 2014 eruption correspond to sulfur isotopic equilibration temperatures from 270 to $281{ }^{\circ} \mathrm{C}$ calculated using the following equation (Ohmoto and Rye 1979; Ohmoto and Lasaga 1982),
$1000 \ln \alpha_{\text {anhydrite-pyrite }}=6.063\left(10^{6} / \mathrm{T}^{2}\right)+0.56(\mathrm{~T}$ in $\mathrm{K})$,

where $\alpha_{\text {anhydrite-pyrite }}$ represents the isotope fractionation factor between anhydrite and pyrite.

This temperature range is consistent with those inferred from the hydrothermal mineral assemblage (e.g., pyrophyllite and rutile) of the 2014 pyroclastic materials $\left(200-300^{\circ} \mathrm{C}\right)$ (Hedenquist et al. 1996), as well as the underground temperature of the 1979 crater area calculated based on the sulfur isotopic compositions of volcanic gases related to the 1979 Ontake eruption (more than $250{ }^{\circ} \mathrm{C}$; Ossaka et al. 1983). These ranges are lower than the sulfur isotopic equilibration temperatures of the 1979 eruption $\left(314-394{ }^{\circ} \mathrm{C}\right.$ ) calculated based on the sulfur isotopic values of HCl-S and Pyrite-S (Kusakabe et al. 1982) with Eq. 3. Sugiura et al. (1980) and Kusakabe et al. (1982) suggested that these temperatures are unrealistically high for the underground mud reservoir of the 1979 eruption because the clay minerals would be unstable at such high temperatures. They attributed this discrepancy to the incorporation of sulfate minerals with lower sulfur isotopic values [e.g., a gypsum sample $\left(\delta^{34} \mathrm{~S}=+5.1 \%\right.$ ) from a fumarolic area of Mt. Ontake] into the underground materials.

\section{Conclusions}

The pyroclastic material of the $2014 \mathrm{Mt}$. Ontake eruption was composed of altered volcanic fragments, alunite, anhydrite, biotite, cristobalite, gypsum, ilmenite, kaolin minerals, native sulfur, orthopyroxene, plagioclase, potassium feldspar, pyrite, pyrophyllite, quartz, rutile, and smectite. Most of these minerals were likely derived from the acidic alteration zones of Mt. Ontake. The absence of juvenile material in the eruptive products indicates that the eruption was phreatic. The difference in sulfur isotopic values between anhydrite and pyrite from the 2014 eruption indicates isotopic equilibration temperatures ranging from 270 to $281{ }^{\circ} \mathrm{C}$. This temperature range is consistent with that inferred from the hydrothermal mineral assemblage (e.g., pyrophyllite and rutile) of the 2014 pyroclastic materials $\left(200-300{ }^{\circ} \mathrm{C}\right)$. With the exception of the sulfur isotopic compositions of anhydrite, which may have been altered by the incorporation of sulfate minerals in a fumarolic area with lower sulfur isotopic values into the underground materials during the 1979 eruption (Sugiura et al. 1980; Kusakabe et al. 1982), no significant differences in the mineral assemblages or sulfur isotopic compositions of the pyroclastic materials were observed between the 2014 and 1979 Ontake phreatic eruptions, which indicates geochemical similarity in the hydrothermal systems below the crater before each of these eruptions. 


\section{Authors' contributions}

IK carried out the sample collection, sample description and drafted the manuscript. MT performed the sulfur isotope analysis of the samples and helped draft the manuscript. Both authors read and approved the final manuscript.

\section{Acknowledgements}

We thank two anonymous reviewers for their constructive comments and Dr. Teruki Oikawa for editorial assistance. This work was partially supported by a grant from the Program to Disseminate Tenure Tracking System of the Ministry of Education, Culture, Sports, Science and Technology (MEXT), Japan.

\section{Competing interests}

The authors declare that they have no competing interests.

Received: 29 November 2015 Accepted: 22 June 2016

Published online: 13 July 2016

\section{References}

Fry B, Silva SR, Kendall C, Anderson RK (2002) Oxygen isotope corrections for online $\delta^{34} S$ analysis. Rapid Commun Mass Spectrom 16:854-858. doi:10.1002/rcm.651

Hedenquist JW, Izawa E, Arribas A, White NC (1996) Epithermal gold deposits: styles, characteristics and exploration. Resour Geol Special Publication No. 1:17

Holland HD (1965) Some applications of thermochemical data to problems of ore deposits: II. Mineral assemblages and the compositions of ore-forming fluids. Econ Geol 60:1101-1166. doi:10.2113/gsecongeo.60.6.1101

Ikehata K, Maruoka T, Chida K (2014) Sulfur isotope characteristics of the September 2014 eruptive products from Ontake volcano, Japan. In: Abstracts of the Volcanological Society of Japan 2014 Fall Meeting, Supplement: Emergency Academic Session, Fukuoka University, Fukuoka, 2-4 November 2014 (In Japanese)

Imura T, Minami Y, Takahashi R, Imai A, Ohba T, Hayashi S (2014) Mineralogy and S-isotope of Volcanic Ash of the Phreatic Eruption at Ontake Volcano in September 2014. In: Abstracts of the Volcanological Society of Japan 2014 Fall Meeting, Supplement: Emergency Academic Session, Fukuoka University, Fukuoka, 2-4 November 2014 (In Japanese)

Kaneko T, Maeno F, Nakada S (2014) Ontake 2014 eruption: observation from a helicopter. In: Abstracts of the Volcanological Society of Japan 2014 Fall Meeting, Supplement: Emergency Academic Session, Fukuoka University, Fukuoka, 2-4 November 2014 (In Japanese)

Kusakabe M, Mizutani Y, Kometani M (1982) A preliminary stable isotope study of volcanic ashes discharged by the 1979 eruption of Ontake Volcano, Nagano, Japan. Bull Volcanol 45(3):203-209. doi:10.1007/BF02597731
Maruoka T, Koeberl C, Hancox PJ, Reimold WU (2003a) Sulfur geochemistry across a terrestrial Permian-Triassic boundary section in the Karoo Basin, South Africa. Earth Planet Sci Lett 206:101-117. doi:10.1016/ S0012-821X(02)01087-7

Maruoka T, Koeberl C, Matsuda J, Syono Y (2003b) Carbon isotope fractionation between graphite and diamond during shock experiments. Meteorit Planet Sci 38(8):1255-1262

Mayer B, Krouse HR (2004) Procedures for sulfur isotope abundance studies. In: de Groot PA (ed) Handbook of stable isotope analytical techniques, vol 1. Elsevier, Amsterdam, pp 538-596

Miyagi I, Geshi N, Hamasaki S, Tomiya A (2014) Volcanic ash particles from Ontake volcano on September 2014. In: Abstracts of the Volcanological Society of Japan 2014 Fall Meeting, Supplement: Emergency Academic Session, Fukuoka University, Fukuoka, 2-4 November 2014 (In Japanese)

Nakada S, Maeno F, Kaneko T (2014) Eruption sequence of the 27 September 2014 eruption at Ontake Volcano, Japan and the future scenario. In: Abstracts of the Volcanological Society of Japan 2014 Fall Meeting, Supplement: Emergency Academic Session, Fukuoka University, Fukuoka, 2-4 November 2014 (In Japanese)

Ohmoto H, Lasaga AC (1982) Kinetics of reactions between aqueous sulfates and sulfides in hydrothermal systems. Geochim Cosmochim Acta 46:1727-1745. doi:10.1016/0016-7037(82)90113-2

Ohmoto H, Rye RO (1979) Isotopes of sulfur and carbon. In: Barnes HL (ed) Geochemistry of hydrothermal ore deposits, 2nd edn. Wiley, New York, pp 509-567

Oikawa T (2008) Reinvestigation of the historical eruption and fumarolic activity records at Ontake Volcano, central Japan: Misunderstanding reports about the $774 \mathrm{AD}$ and $1892 \mathrm{AD}$ eruptions. Bull Geol Surv Jpn 59(5/6):203-210 (In Japanese)

Ossaka J, Ozawa T, Sakai H, Hirabayashi J (1983) Geochemical study on the volcanic activity of Kiso-Ontake volcano, after the 1979 eruption. Bull Volcanol Soci Jpn 28(1):59-74 2nd series (In Japanese)

Rye RO (2005) A review of the stable-isotope geochemistry of sulfate minerals in selected igneous environments and related hydrothermal systems. Chem Geol 215:5-36. doi:10.1016/j.chemgeo.2004.06.034

Sugiura T, Sugisaki R, Mizutani Y, Kusakabe M (1980) Geochemistry of volcanic ashes, thermal waters and gases ejected during the 1979 eruption of Ontake volcano, Japan. Bull Volcanol Soci Jpn 25(4):231-244 2nd series (In Japanese)

Utada M (1980) Hydrothermal alterations related to igneous activity in Cretaceous and Neogene formations of Japan. Mining Geol Spec Issue 8:67-83

Williams SN, Sturchio NC, Calvache VML, Mendez FR, Londoño CA, García PN (1990) Sulfur dioxide from Nevado del Ruiz volcano, Columbia: total flux and isotopic constraints on its origin. J Volcanol Geotherm Res 42:53-68. doi:10.1016/0377-0273(90)90069-R

\section{Submit your manuscript to a SpringerOpen ${ }^{\odot}$ journal and benefit from:}

- Convenient online submission

- Rigorous peer review

- Immediate publication on acceptance

- Open access: articles freely available online

- High visibility within the field

- Retaining the copyright to your article

Submit your next manuscript at $\mathbf{s p r i n g e r o p e n . c o m ~}$ 